\title{
O PAMPA, O CAVALO, A PEDRA E O TRABALHO
}

Jussemar Weiss Gonçalves ${ }^{1}$

Letícia de Faria Ferreira ${ }^{2}$

O trabalho nas fazendas de criação de gado no sul do Brasil, especialmente nas regiões sul e da campanha do Rio Grande do Sul, onde se chama culturalmente o pampa gaúcho foi, e ainda é em algumas localidades, marcado por um ritmo que mistura o trabalho com aventura, uma conjunção carregada de ambivalências. Ambivalências que precisam ser descritas para não correrem o risco de criarem noções equivocadas sobre essa relação trabalho/aventura. Pois, se historicamente a figura do gaucho simbolizou o homem que circulava pelo pampa com certa independência e mantendo-se vivo pela destreza e pela coragem, envolvido com guerras de território, adestramento de cavalos xucros, arrebanhando quase que livremente o gado que não fora marcado, também é uma figura cada vez mais rara, que tem seu oficio hoje atravessado pelas exigências da produção capitalista.

O nosso trabalho de pesquisa tem buscado entender o gaucho com uma forma de vivência que se modifica no tempo e no espaço da campanha do cone-sul. O gaucho não prefigura as manifestações do sujeito, mas é o movimento de transformação do espaço pampa que ocasiona, também, alterações no sujeito, principal articulador das atividades da pecuária nesta região. Assim se nos séculos XVII e XVIII temos momento de instituição do sujeito com suas práticas, habilidades e vivências, a partir da presença massiva do rebanho bovino que possibilita mesmo a existência desse trabalhador esporádico,pois uma de suas características e seu caráter itinerante e aventureiro. Nos séculos vindouros, tanto a quantidade como as formas de cuidados com os rebanhos vão sofrer fortes mudanças e com elas o gaucho passará por uma transfiguração.

Procuramos, portanto, entender o gaúcho ou gaucho ${ }^{3}$ do ponto de vista histórico cultural, como a própria dubiedade linguística da expressão anuncia, como um ser de fronteira, algo como um passageiro de territórios, como diria Walter Benjamim. Entretanto, não se tratam de fronteiras em seu sentido de divisa territorial, mas no sentido de intersecção entre temporalidades, culturas e também entre os países do Uruguay, Argentina e do Sul do Brasil. O gaucho constitui-se como personagem da

\footnotetext{
${ }^{1}$ Universidade Federal do Rio Grande, Brasil.

${ }^{2}$ Universidade Federal da Fronteira Sul, Brasil.

${ }^{3}$ Procuramos usar a palavra gaucho, em itálico e em espanhol para diferenciar esse personagem histórico cultural do gaúcho morador do Rio Grande do Sul.
} 
história da região do pampa através de suas práticas que combinavam saberes indígenas e de homens brancos, costumes europeus e africanos, reconstruindo uma mundo particular, a partir de uma visão própria de sociabilidade. Um ser a meio caminho entre uma sociedade em formação e a natureza pampeana. Nômade em uma sociedade que se define pela propriedade do solo. A fronteira está em si mesmo, e não no território que ele ocupa. Esta fronteira que o constituiu o faz mesmo em sua época um tipo social particular, já que, embora necessário para o tipo de comércio, em nenhum momento foi aceito pela sociedade da época de forma integral.

As formas de trabalho que foram sendo gestadas por esse passado agrário e carregado de particularidades em sua estrutura econômica (contrabando, charqueadas, latifúndio agropastoril) ainda são possíveis de serem visualizadas no contexto rural da região sul do Rio Grande do Sul, pois mesmo levando-se em conta todas as modificações trazidas pela modernização das formas produtivas das estâncias e fazendas de pecuária, muito do ideário que compõe os métodos tradicionais de trabalho são remanescentes nesses locais. Portanto, será o sujeito que opera nas formas de trabalho tradicionais que são utilizadas nas fazendas que trataremos no texto a partir de observações etnográficas.

Nosso breve relato procura aproximar-se do que propõem Clifford e Marcus (1991) "la credibilidad del etnógrafo radica em la veracidade de su experiência de campo, pero también - o sobre todo - en su capacidad para convencer a los otros sobre la autenticidad de lo que el há experimentado." Deste modo, começaremos pelos meios de trabalho que no atual processo de modernização das fazendas acabam sendo quase extintos, seja o ofício quanto seu artesão. ${ }^{4}$

Conhecemos o Zé das Pedras em 2008 quando o contatamos para saber se ainda trabalhava em construções de casas e galpões feitos de pedras e reformas de antigas cercas de pedra, afinal era indicado e reconhecido em toda a cidade pelo seu trabalho e pela tradição familiar de longa data. Também já tínhamos ouvido falar da fama da "família do Brasileiro" como os únicos cantareiros ainda em atividade. "Os filhos do

\footnotetext{
${ }^{4}$ Artesão - buscamos uma aproximação do sentido de trabalho artesanal em Wrigth Mills, pois talvez seja umas das definições mais apropriadas para definir o trabalho do gaucho. Mills opõe à atitude burocrática, formalista e instrumental, a uma prática artesanal, e principalmente, rejeita a separação entre a vida e o trabalho do artesão.
} 
Brasileiro" é como são conhecidos os irmãos e o próprio Zé das Pedras, pois o seu pai era apelidado de Brasileiro e assim chamado na cidade porque ironicamente tinha nascido no lado castelhano, como diz. Tanto a fama quanto os apelidos foram passados de boca em boca na pequena cidade encravada na fronteira com o Uruguay.

Zé tem 46 anos e trabalha desde que se lembra. Sua memória da infância é de muito trabalho ao lado do pai, do tio e dos irmãos, sempre com pedra, gosta de reforçar. Ensinar o ofício para os filhos sempre foi uma preocupação do seu Brasileiro, fato que é recordado com muita afetividade por Zé, ao lembrar de seu falecido pai. O trabalho de recolher pedras no leito de arroios e sangas ou em pedreiras escondidas nas coxilhas dos campos e carregá-las até onde seria construída uma obra exigia não apenas força física para carregar pedras manualmente de quase meia tonelada, mas um saber, uma técnica específica que a faz rolar sobre si, sendo calçada por outras pequenas pedras antes que complete a volta e o tombo sobre si mesma, fazendo com a próxima etapa sempre seja facilitada, pois essa pequena pedra servia como um calço que mantinha parte da grande pedra erguida e, consequentemente, mais vulnerável ao próximo tombo. Esse saber carregar uma pedra com a força do próprio corpo, sem empregar nenhuma máquina exceto uma alavanca de ferro maciço, por mais estranho que pareça para quem nunca visualizou, exige um treino e uma técnica muito particulares e inventivos, pois permite que a tarefa seja realizada em distintas e adversas situações.

Para o Zé essa foi a herança maior que seu pai lhe deixou: um ofício, uma profissão. Mesmo considerando que quando criança era duro o trabalho, lembra que a diversão junto com seus irmãos era recompensadora e que jamais pensou em fazer outra coisa da vida, tamanho é seu gosto por realizar obras com pedras em estado natural.

São muitos significados para o trabalho. Esse legado de pai para filho e o amor que Zé declara pelas pedras e pelas formas e cores que cada uma particularmente tem faz dele um engenhoso bricoleur, que tem em suas mãos essa matéria bruta e sabe coloca-la no exato lugar da parede inexata que constrói. Cada pedra entra para a parede conforme a beleza e o encaixe com as demais pedras, mantendo sempre seu formato original. Seu trabalho não tem sentido sem o tempo de escolha das pedras que irão compor sua obra, sem essa técnica que se constrói em conjunção com a matéria que usa.

É nesse percurso de encontrar a pedra, trazê-la para próximo da obra, depois ir compondo paredes com as formas condizentes das pedras que o ofício do cantareiro vai sendo realizado. Uma composição delicada e custosa, que requer tempo, saber e dedicação. Um trabalho que cada vez tem menos espaço no mundo das construções 
rápidas, práticas e de menor custo possível. As reformas nas cercas de pedras construções de pedra bruta com altura media de um metro e meio, edificadas em sua maior parte por trabalho escravo e largamente utilizadas no século XIX para demarcar os limites das propriedades agrárias - são a outra fonte de trabalho do Zé, no entanto, é ainda mais suscetível de extinção que as construções de casas.

A substituição ocorrida durante praticamente todo o século $\mathrm{XX}$ das cercas de pedras por outras que utilizam arames de metal e estacas de madeira cujo custo e praticidade só perdem para as ainda mais recentes cercas elétricas que necessitam apenas um fio de arame ligado a um pequeno aparelho que gera um choque elétrico repulsivo. Essa mudança nos materiais usados para construção é o principal motivo da redução desse trabalho de reformas de cercas para os cantareiros que tinham como função a manter de pé as seculares cercas de pedras. Para Zé, apenas um que outro proprietário preocupa-se com a conservação das cercas de pedra por que o custo da mão de obra não é compensatório.

Assim, se por um lado, o trabalho realizado por Zé das Pedras que antes era feito por seu pai, que aprendeu com seu avô enfrenta o desinteresse dos proprietários em contrata-los, por outro lado, o próprio personagem do cantareiro está em franco processo de extinção. Segundo nos contou Zé, a sua maior tristeza atualmente é não conseguir ensinar sua profissão para ninguém, não poder passar adiante a tradição familiar que lhe foi passada, a memória das técnicas de coleta e construção com pedra em estado natural que carrega desde o tempo de seu avô. Tendo duas filhas que residem na cidade e quatro irmãos, estes últimos pararam de trabalhar com pedra por motivos de saúde e, portanto, não puderam continuar o oficio. Ocorre então que a perspectiva de Zé não é das melhores, afinal ele mesmo acredita não ter fôlego para continuar por muito tempo considerando que seu serviço demanda muita força física.

Enfim, as observações que realizamos com Zé relatam uma pequena parte de seu ofício, o qual consegue manter através de um contrato e outro, mas o futuro de sua profissão parece condenado ao desaparecimento, seja por conta da falta de sucessores para aprender a sua técnica, seja pelo alto custo desse tipo de trabalho ocasionado pelo longo tempo que demanda sua realização e, por conseguinte, a queda na procura. Ainda que raras e merecedores de preservação histórica, as cercas, as casas, os banheiros de gado e os galpões, obras reformadas ou realizadas pela família dos Brasileiros, foram vitimas nos últimos anos de um terrível predador: a plantação de monoculturas de árvores para produção de celulose ao comprar inúmeras propriedades rurais na região, 
impiedosamente colocou-as debaixo da terra. Literalmente, grandes tratores de esteira enterraram tudo que pudesse estar ocupando o espaço de plantação de eucaliptos, fossem cercas de pedras seculares, fossem casarios construídos pelas mãos dos "Brasileiros". Quando lembra disso, Zé não esconde a tristeza e desabafa "além de não ter quem siga fazendo, ainda estão destruindo o que já foi feito.”

É possível perceber nas conversas entre os gaúchos que já trabalharam como peões de fazendas em épocas passadas (anos 60, 70 e 80) uma distinção entre o trabalho que era realizado no passado e o que é atualmente. As durezas que era a falta de conforto, de luz elétrica, de água encanada, etc., e as exigências dos afazeres são ressaltadas como um aspecto que marca a vida regressa. No entanto, são positivamente recordadas as relações de amizades entre patrões e empregados, entre vizinhos e entre os trabalhadores de uma mesma região. A memória do lazer e das diversões "de antigamente" são muito valoradas, pois segundo relatam, alguns eventos como carreiras de cavalo, marcação de gado e bailes de campanha, reunia a todos que tinham como intuito apenas de se divertir, sem violência e maiores separações de classe.

Até os anos 90, quando um peão era admitido em uma fazenda, o que seria seu trabalho, qual jornada, por quanto tempo e o salário não tinham definições muito precisas e muito menos qualquer regulamentação legal. Assim que, o trabalho sempre começava antes do dia clarear, pois era estipulado pelos saberes tradicionais que o leite devia ser tirado antes do amanhecer para que os terneiros (bezerro) não ficassem presos quando o sol saísse. Essa jornada se prolonga até escurecer, pois há funções que também devem ser feitas ao cair do dia, tal como separar as vacas dos seus terneiros para no outro dia ordenhar, aguar plantas, colocar lenha para dentro de casa e dar comida para alguns animais são, por exemplo, tarefas habituais de fim do dia. Neste itinerário, há, porém, os momentos consagrados para si e para o lazer, momentos estes que até hoje são recordados com muito gosto. À hora do mate pela manha, acompanhado de um churrasco assado na beira de um fogo no galpão da fazenda e a lida com os cavalos, as domas e treinos destes animais, são revisitados como eventos quase dadivosos permitidos pelos proprietários, pequenos deleites que atualmente estão praticamente em desuso. 
O guri foi entregue para o padrinho, já era, no dizer local "bem campeirinho", $\mathrm{e}$ poderia ser útil nas tarefas da fazenda - tocar as vacas de leite, fazer o fogo para aquecer a água do mate no galpão, tocar os cavalos para a mangueira e até nas lidas da casa poderia ajudar. No dia em que seu pai lhe trouxe, recomendou ao compadre fazendeiro que podia colocar o guri no serviço, que tinha outros 15 filhos em casa e estava deixando este para ir se criando e aprendendo uma profissão.

O breve relato acima foi feito por Pedro, o menino de antes, hoje um homem com 62 anos. Diz respeito a uma situação muito frequente na campanha gaúcha dos anos 40 e 50 - ainda que situações similares sejam possíveis de acontecer atualmente. Essa profissão seria a mesma que o próprio pai já desempenhara na fazenda, ou seja, peão do campo pouco e mal remunerado, sem direitos e proteções exceto a benevolência do patrão. Uma profissão, tal como a do cantareiro herdada pela tradição familiar, onde saberes e técnicas geralmente são passadas de pai para filho e, as novidades em termos de tecnologia e práticas são admitidas com muita resistência.

Os requisitos atuais para contratação de um peão já não corresponde em muitos estabelecimentos aos mesmos das décadas passadas, portanto, podemos observar que para muitos trabalhadores deixar seus métodos que conciliavam o trabalho com a aventura - atirar laço correndo a cavalo para curar um animal doente, domar um cavalo xucro com a força dos braços, laçar, marcar e castrar em rituais como as jerras e marcações ${ }^{6}$ de gado que mais que um trabalho eram uma festa - podem significar o abandono dessa profissão como também uma adaptação marcada por um sentimento saudosista.

Como relata Pedro, "no meu tempo é que se era gaúcho, laçava campo a fora, agora para não perder peso, os animais tem que serem tocados bem devagarzinho, até abanando lencinhos. " Pedro tornou-se adolescente, adulto e permaneceu na fazenda que o recebeu quando criança durante 26 anos. Durante esse tempo, saiu apenas para prestar serviço militar, apesar da contrariedade de seu patrão que fizera diversas tentativas de dissuadi-lo. Nesse período de tempo que foi peão da fazenda nunca teve direitos

\footnotetext{
${ }^{5}$ Campeirinho: diminutivo de campeiro, ou seja, aquele que conhece os trabalhos no campo, a montaria do cavalo e o cuidado com o gado.

${ }^{6}$ Jerras ou marcações de gado. Uma festa muito comum até cerca de duas décadas atrás, que consistia em marcar, castrar e assinalar o gado e reunia toda vizinhança para pegar o animal no laço, derrubá-lo com a força de dois ou mais homens. Esses encontros sempre são regados de churrasco, cachaça e pastel.
} 
trabalhistas assegurados, nem salário com valor fixo e horário de trabalho estabelecido. As suas funções também eram as mais variadas, pois além de sair para o campo a cavalo, podia ser cortador de lenha, encarregado de tirar leite e até mesmo ajudar a fazer doces caseiros em tachos de cobre (no caso, mexer o doce com uma imensa colher de pau e cuidar do fogo de chão) atividade muito freqüente no inverno da campanha gaúcha.

Os labores na fazenda eram diversos para Pedro, desde criança se acostumara a ser chamado para todo tipo de serviço, alguns achava divertido, principalmente aqueles que envolviam a lida com animais, outros afazeres eram penosos e cansativos. $\mathrm{E}$ foi por conta destes últimos que, quando pode, foi embora da campanha, deixando para trás a fazenda e a saudade boa de andar a cavalo. Foi embora, e como espécie de indenização tratada nos termos da relação pessoalizada, onde quem define o que vai dispor é a benevolência do patrão, ou seja, sem envolver nada que se aproxime de justiça trabalhista, carteira de trabalho ou algo que pareça, sendo tudo arranjado dentro do uma espécie de acordo de lealdade e gratidão, que pode sair bem custoso para uma das partes...

Assim, depois de tão longo tempo de trabalho, o patrão ajudou Pedro a montar um bar na cidade. Depois foi ser pedreiro, tocou gaita em bailes de campanha, fez vários tipos de trabalhos, casou, teve filhos e hoje é dono de um pequeno armazém, mas não deixa de andar a cavalo e fazer as lides do campo na pequena parcela de terra de sua esposa. Por que para um gaucho, parece impossível ficar sem o cavalo.

Pedro e Zé, levando em conta as particularidades de cada uma de suas profissões, nos remetem ao que em outra ocasião procurarmos definir: o gaucho, sujeito geralmente filho de antigos peões, pobres e de baixíssima escolarização que desde tenra idade participava junto com seu pai ou com outros peões das lidas na estância. Dessa maneira, tendo vivido sempre o trabalho como modo de vida, para além de uma simples tarefa a partir da qual ganhará sua subsistência, acaba por ter dificuldades em se reconhecer como um sujeito de direitos. Essa vivência com um trabalho que é ao mesmo tempo um estilo de vida, valida situações nas fazendas que estão carregadas de heranças orientadas pelos sistemas de trabalho do passado. Quando conversamos com 
Zé ou com Pedro, é a memória que age como espécie de filtro, daquilo que merece ser lembrado ou, o que, por motivos diversos, pode ser bloqueado. ${ }^{7}$

É por essa memória do trabalho artesanal que, não só filtra e bloqueia, mas que vai constituíndo-se no decorrer do tempo, deixando possibilidade e espaço para que as tradições que são passadas de geração a geração sejam também elas capazes de sobreviver e serem adaptar a novas circunstâncias, podendo serem continuadas ou até mesmo "descontinuadas" conforme o grau de alteração. (Bastide, 1970).

\section{Referências}

BASTIDE, Roger. "Mémoire collective et sociologie du bricolagem". In: L'Année Sociologique, v. 21. Paris: P.U.F., 1970. p. 65-108.

CLIFFORD, James e MARCUS, George. E. Retoricas de la Antropologia. Madrid: Ediciones Júca, 1991.

FERREIRA, Letícia de Faria; GONÇALVES, Jussemar Weiss. "Lealdade e direitos: fragmentos da memória no mundo do trabalho na campanha gaúcha”. In: Anais da Reunião de Antropologia do Mercosul. Buenos Aires: UNSAM, 2009.

HALBWACHS, Maurice. A memória coletiva. São Paulo: Editora Centauro, 2006.

Recebido em: 17/04/2012

Aprovado em: 22/06/2012

\footnotetext{
${ }^{7}$ Ver Ferreira e Gonçalves, 2009.
} 